\title{
Exames laboratoriais complementares indicados no apoio ao diagnóstico do linfoma difuso de grandes células $B$ (LDGCB)
}

\author{
Laboratories analyses indicated in additional support for the diagnosis of diffuse \\ lymphoma B large cell (DLBCL)
}

Roberta dos Santos Guilherme', Luciana Zambeli Caputto ${ }^{1,2}$, Alexandre Luiz Affonso Fonseca', Juliana Pereira ${ }^{3}$, Fernando Luiz Affonso Fonseca ${ }^{1,4}$

\section{Resumo}

0 linfoma difuso de grandes células B (LDGCB) é um linfoma agressivo, heterogêneo, mas potencialmente curável com quimioterapia multiagente; compreende cerca de 30 a 40\% dos linfomas não Hodgkin; ocorre principalmente nos indivíduos com mais de 70 anos e raramente em crianças. 0 LDGCB pode surgir como um evento de novo ou representar uma progressão ou transformação de um linfoma menos agressivo. O International Prognostica Index (IPI) é utilizado como um fator preditivo das conseqüências clínicas para o paciente, porém, isolado não é capaz de prever com certeza o resultado de um tratamento para pacientes individuais, então se faz necessária a utilização de outros exames laboratoriais, ditos especiais para melhor diagnóstico e prognóstico dessas neoplasias. 0 objetivo deste trabalho foi verificar os principais exames laboratoriais complementares no apoio ao diagnóstico do LDGCB, bem como os avanços dessas análises, destacando seus princípios, vantagens e desvantagens na rotina laboratorial. 0 anátomo-patológico, a citogenética clássica, a citogenética molecular, as técnicas de biologia molecular, a imunohistoquímica e a imunofenotipagem são os exames aplicados no diagnóstico desta patologia. 0 exame de anatomia patológica pode ser utilizado como de referência, pois delineia o diagnóstico do paciente e auxilia na escolha dos exames complementares. A marcação por imunohistoquímica realiza uma avaliação direta das células neoplásicas, pois pode identificar os subtipos centro germinativo (GC) e não GC dos LDGCBs e predizer a sobrevivência com uma expressão similar a de expressão de genes por microarrays, considerada a principal técnica de biologia molecular empregada no estudo dos LDGCB. A citogenética clássica permite observar outros marcadores além dos específicos para o LDGCB, como as translocações t $(14 ; 18)$ e t $(11 ; 18)$. A imunofenotipagem (citometria de fluxo) permite a caracterização do estágio de maturação das células malignas, contribuindo para a definição da linhagem celular. Contudo, a técnica de FISH além de identificar marcadores genéticos do LDGCB, permitir que esta análise seja feita em amostras acondicionadas em parafina e em células não viáveis.

Palavras-chave: Linfoma; biópsia; citogenética; citometria de fluxo; biologia molecular.

\begin{abstract}
The lymphoma diffuse large B cell (DLBCL) is an aggressive lymphoma, heterogeneous but potentially curable with chemotherapy multivalent, comprises about 30 to $40 \%$ of non-Hodgkin's lymphomas, mainly occur in individuals over 70 years and rarely in children. The DLBCL can emerge as an event of new or represent a progression or transformation of a less aggressive lymphoma. The International Prognostica Index (IPI) is used as a factor predictive of the clinical consequences for the patient, but alone is not able to predict with certainty the result of a treatment for individual patients then it is necessary to the use of other laboratory tests, said complemetary to better diagnosis and prognosis of these neoplasms. The objective of this work was to achieve a bibliographic survey of the main laboratory tests indicated support for dignostic of DLBCL highlighting its principles, advantages and disadvantages in the routine laboratory. The anatomy-pathological, the classical cytogenetics, molecular cytogenetics, the techniques of molecular biology and immunophenotyping exams are applied in the diagnosis of this condition. An examination of pathological anatomy can be used as reference, because outlines the diagnosis of the patient and helps in the choice of additional tests. The marking by immunohistochemistry conducts a direct assessment of neoplastic cells, it can identify the subtypes germinative center (GC) and not the GC DLBCLs and predict the survival with a similar expression of the gene expression by microarray, considered the main technique of molecular biology employed in the study of DLBCL. The classical cytogenetic markers can be observed other than those specific to the DLBCL such as the translocation $t(14 ; 18)$ and $(11 ; 18)$. The immunophenotyping (flow cytometry) allows the characterization of the state of maturation of malignant cells contributing to the definition of the cell line. However, the technique of FISH and identify genetic markers of DLBCL, allow this review is made on samples wrapped in paraffin and non-viable cells.
\end{abstract}

Keywords: Lymphoma; biopsy; cytogenetics; flow cytometry; molecular biology.

Recebido: 19/06/2008

Aprovado sem modificação: $21 / 10 / 2008$

Curso de Especialização em Análises Clínicas do Instituto de Pesquisa e Ensino de São Paulo (IPESSP), São Paulo (SP)

2 Laboratório Chromos de Citogenética, São Paulo (SP)

${ }^{3}$ Disciplina de Hematologia e Hemoterapia da Faculdade de Medicina da Universidade de São Paulo (FMUSP), São Paulo (SP)

${ }^{4}$ Laboratório de Análises Clínicas da Disciplina de Hematologia e Oncologia da Faculdade de Medicina do ABC (FMABC), Santo André (SP)

Endereço para correspondência: Fernando Luiz Affonso Fonseca/Laboratório de Análises Clínicas da FMABC, Anexo 3 - Avenida Lauro Gomes, 2000,

CEP: 09060-870 - Santo André (SP), Telefone: (11) 4993-5488 - E-mail: laboratoriofmabc@yahoo.com.br 


\section{Introdução}

O linfoma difuso de grandes células B (LDGCB) é um linfoma agressivo, heterogêneo, mas potencialmente curável com quimioterapia multiagente; corresponde a uma proliferação difusa de grandes células B neoplásicas, compreendendo cerca de 30 a 40\% dos linfomas não Hodgkin nos adultos dos países ocidentais. Acomete principalmente os indivíduos acima de 70 anos, mas já foi encontrado em crianças. Este linfoma pode surgir como um evento de novo ou de uma progressão ou transformação de um linfoma menos agressivo. A imunodeficiência também é um fator de risco significante.

As neoplasias de célula B madura tendem a imitar estágios de diferenciação de células B normais. O linfoblasto B diferencia-se em uma célula pré-B, que ao se ligar ao antígeno sofre uma transformação blástica, prolifera e diferencia-se em plasmócitos secretores de anticorpos IgA ou IgG e células B de memória. A combinação de uma alta taxa proliferativa, expansão clonal das células B e a presença de mecanismos mutacionais é um ambiente propício para a transformação maligna.

O LDGCB expressa vários marcadores específicos de linfócitos B como CD19, CD20, CD22 e CD79a, entre outros, de acordo com o estágio de maturação da célula B.

A maioria dos casos de LDGCB tem um rearranjo dos genes da cadeia pesada e da cadeia leve da imunoglobulina e apresentam mutações somáticas na região variável. A t (14;18) ocorre em 20 a 30\% dos casos e na maioria, implica em uma menor taxa de sobrevida.

O LDGCB geralmente muda a arquitetura normal dos nódulos linfáticos ou tecidos extranodais em um padrão difuso, sendo composto por células linfóides grandes transformadas. Citologicamente, estas células podem ser divididas em variantes morfológicas de acordo com a morfologia celular, tamanho da célula, morfologia do núcleo, quantidade de citoplasma e presença de nucléolo. Pode acometer vários tecidos ou órgãos ${ }^{1}$.

A classificação dos neoplasmas de células B maduras é baseada na utilização das informações disponíveis para definir a doença, como os resultados dos laudos morfológicos, da imunofenotipagem, da análise citogenética, análise molecular, hibridação fluorescente in situ (FISH) entre outros. Na classificação Organização Mundial de Saúde (WHO), as neoplasias de células B maduras são listadas de acordo com sua apresentação clínica e características imunogeneticas ${ }^{1}$.

O International Prognostic Index (IPI) baseado em parâmetros clínicos é fortemente preditivo das conseqüências clínicas, mas sozinho não é capaz de prever com certeza o resultado de um tratamento para pacientes individuais, refletindo somente a biologia do tumor de maneira indireta. Várias tentativas têm sido feitas com o objetivo de aumentar a taxa de sobrevivência destes pacientes, porém sem sucesso ${ }^{2}$.

Alguns exames complementares são utilizados no diagnóstico de LDGCB como anatomia patológica, citogenética clássica, citogenética molecular, biologia molecular, imunohistoquímica e imunofenotipagem. Cada um destes exames possui suas vantagens e desvantagens, porém, juntos ajudam a concluir o diagnóstico do paciente e auxiliam na melhor escolha do tratamento terapêutico a ser utilizado.

Este trabalho apresenta as técnicas mais especializadas no diagnóstico de LDGCB, destacando seus princípios básicos, indicações, vantagens e desvantagens.

\section{Aspectos do LDGCB}

\section{Conceito}

O linfoma difuso de grandes células B corresponde a uma proliferação difusa de grandes células B linfóides neoplásicas, com tamanho nuclear igual ou excedendo o de núcleos de macrófagos normais ou tendo o dobro do tamanho do núcleo de linfócitos normais ${ }^{1}$.

\section{Morfologia e classificação}

De acordo com Gatter e Warnke ${ }^{1}$ estudando alguns casos de LDG$\mathrm{CB}$, estes geralmente mudam a arquitetura normal dos nódulos linfáticos ou tecidos extranodais em um padrão difuso. O envolvimento dos nódulos linfáticos pode ser completo, parcial, interfolicular, ou menos comumente sinusoidal. O tecido mole perinodal está freqüentemente infiltrado e bandas de esclerose finas ou amplas podem ser observadas. O LDGCB é composto de células linfóides grandes transformadas. Citologicamente, eles são diversos e podem ser divididos em variantes morfológicas. Porém, a distinção entre estas variantes geralmente apresenta baixa reprodutibilidade intra-observador e interobservador. Os parâmetros imunofenotípicos e genotípicos não tem ajudado a delinear subtipos morfológicos distintos, com raras exceções. Assim, patologistas têm que escolher entre o uso somente do termo linfoma difuso de grandes células B ou o uso de uma variante morfológica específica. Sendo a variante morfológica mais comum, o centroblasto. Raras variantes têm sido descritas com estroma mixóide, matriz fibrilar, pseudorosetas, grânulos citoplasmáticos, projeções de microvilos e junções intercelulares. Casos de granulomatose linfomatóide com exposição de células malignas representam progressão para uma variante do LDGCB. O surgimento de células com tamanho médio deve requerer estudos adicionais para excluir variantes de leucemias extramedulares e linfoma de Burkitt.

\section{Variantes morfológicas}

\section{a) Centroblástico}

Esta variante é composta de células linfóides com tamanho variando de médio a grande, com núcleo vesicular oval ou quadrado, cromatina fina e de dois a quatro nucléolos ligados a membrana. O citoplasma é geralmente escasso e varia de anfofílico a basofílico. Esta variante pode ter uma aparência monomórfica ou polimórfica. O linfoma centroblástico inclui as variantes monomórficas e polimórfica, como definido na classificação de Kiel. Em alguns casos as células podem se apresentar multilobuladas, ou então células como centroblasto podem estar mistu- 
radas com células multilobuladas e até $90 \%$ imunoblastos, produzindo um infiltrado celular marcadamente polimórfico.

\section{b) Imunoblástico}

A maioria das células (mais de 90\%) nesta variante são imunoblastos com nucléolo único centralmente localizado e uma quantidade apreciável de citoplasma basofilico. Imunoblastos com diferenciação plasmocitóide podem também estar presentes. Laudos clínicos e/ou imunofenotípicos podem ser essenciais na diferenciação desta variante do envolvimento extramedular por uma variante plasmablástica da célula de mieloma do plasma.

\section{c) Células T/Histiócitos}

Nesta variante a maioria das células são células $T$ não variantes com ou sem histiócitos e menos de 10\% de células B neoplásicas grandes estão presentes. Os histiócitos podem ou não ter aparência epitelióide. As células grandes podem assemelhar-se a células L\&H, centroblastos, imunoblastos ou células Reed-Sternberg. Células B pequenas são raras e pouco freqüentes. Áreas com número aumentado de células $B$ pequenas podem permitir a associação com Linfoma nodular predominantemente linfoma de Hodgkin (LNPLH), principalmente se um padrão de crescimento nodular impreciso estiver presente. $O$ padrão de crescimento é predominantemente difuso e uma fina fibrose reticular está freqüentemente presente.

\section{d) Anaplástico}

Esta variante do LDGCB é caracterizada por células muito grandes quadradas, ovais ou poligonais com núcleos pleomórficos bizarros, os quais devem assemelhar-se a células Reed-Sternberg. As células podem crescer em um padrão coesivo imitando um carcinoma e podem mostrar um padrão sinusoidal de crescimento.

A classificação dos neoplasmas de células B maduras é baseada na utilização das informações disponíveis para definir a doença como os resultados dos laudos morfológicos, da imunofenotipagem, da análise citogenética, análise molecular, FISH entre outros. Na classificação WHO, os neoplasmas de células B maduras são listados de acordo com sua apresentação clínica e padrões imunogenéticos³.

Novas pesquisas usando análise de DNA microarrays para avaliar a expressão gênica sugerem que os padrões de expressão gênica podem identificar subtipos do LDGCB, que estão relacionados com diferentes estágios de diferenciação da célula $\mathrm{B}^{3-4}$. Desta maneira o LDGCB pode ser dividido em:

- GCB (centro germinativo da célula B): apresentando um perfil de expressão que se assemelha ao de células B normais do centro germinativo.

- $\quad A B C$ ou ABL (tipo célula B ativada): apresentando um perfil de expressão que assemelha-se ao de células B do sangue periférico ativadas por estímulos mitogênicos.

- Tipo 3: representa um grupo heterogêneo ainda pouco definido.
Os subtipos $\mathrm{ABC}$ ou $\mathrm{ABL}$ e o tipo 3 também podem ser denominados de subtipo não-GCB

\section{Epidemiologia}

O linfoma difuso de grandes células B (LDGCB) constitui cerca de $30-40 \%$ dos linfomas não-Hodgkin nos adultos dos países ocidentais. Nos países desenvolvidos eles representam uma proporção maior dos linfomas. Eles são encontrados mais comumente nos indivíduos com média de idade de 70 anos, porém de forma variável, tendo já sido encontrado em crianças. O LDGCB é ligeiramente mais comum em homens do que nas mulheres, e nas últimas décadas sua incidência tem aumentado, não apresentando relação com o índice de pacientes soros positivos $^{1}$.

\section{Etiologia}

Segundo Gatter e Warnke ${ }^{1}$, estudando alguns casos em pacientes com LDGCB concluíram que a causa ou causas do LDGCB permanecem desconhecidas. Surgem geralmente como um evento de novo, conhecido como evento primário, mas podem representar uma progressão ou transformação, referido como evento secundário, de um linfoma menos agressivo, como por exemplo, leucemia linfocítica crônica e/ou linfoma linfocítico pequeno (LLC/LLP), linfoma folicular, linfoma da zona marginal de célula B ou linfocítico nodular predominantemente linfoma de Hodgkin (LNPLH). A imunodeficiência é um fator de risco significante. No LDGCB os casos de imunodeficiência são mais freqüentemente causados pelo vírus Epstein-Barr (EBV) positivo do que esporádicos.

\section{Fisiopatologia}

As neoplasias de célula B madura tendem a imitar estágios de diferenciação de células B normais, e assemelhar-se a estágios de célula B normal sendo a base para a classificação e nomenclatura das neoplasias de células B.

As células pré-B ocupam os folículos linfóides primários e zonas do manto folicular, também chamadas de células B recirculantes. Ao encontrar o antígeno, as células pré-B sofrem transformação blástica, proliferam e por último maturam em células plasmáticas que secretam anticorpos IgG ou IgA e células B de memória. Os blastos formados de células pré-B que encontraram o antígeno migram para o centro de um folículo primário e preenchem as células dendríticas foliculares, formando o centro germinativo. Os blastos do centro germinativo são chamados de centroblastos. Em muitos destes blastos falta a imunoglobulina de superfície e a expressão de BCL2 está bloqueada, deixando estas células e sua progênie susceptíveis a morte celular por apoptose. Os centroblastos expressam a proteína BCL6, um fator de transcrição nuclear do tipo zinc-finger que também é expresso por centrócitos, mas não pelas células pré-B ou de memória, e também por células do plasma ou do manto. 
No centro germinativo mutações somáticas ocorrem na região variável do gene da imunoglobulina (IGV), as quais alteram a afinidade do antígeno para o anticorpo que será produzido pela célula, resultando em uma diversidade intraclonal alta em uma população de células derivadas de alguns precursores. Adicionalmente, algumas células trocam a produção de IgM para IgG ou IgA. Por meio destes mecanismos, a reação no centro germinativo origina uma melhor ligação do anticorpo IgG ou IgA na resposta imune primária ou secundária.

O gene BCL6 também sofre mutação somática no centro germinativo, em uma menor freqüência do que é visto nos genes das imunoglobulinas. Mutações na região IGV do gene com diversidade intraclonal é uma marca das células do centro germinativo, e ambas mutações na região IGV do gene e no bcl6 servem como marcadores de células usados por meio do centro germinativo. A maioria dos linfomas de células B grande são compostos de células que em parte assemelham-se a centroblastos que têm a região IGV e o gene BCL6 mutados, consistente com o surgimento de células expostas no centro germinativo. As células do linfoma de Burkitt são BCL6+ e têm os genes IGV mutados, e por isso acredita-se que correspondam aos blastos do centro germinativo. O linfoma de Burkitt e o linfoma de grandes células B correspondem a células com alto nível de proliferação celular e tendem a ser clinicamente tumores agressivos.

Os centroblastos maturam em centrócitos aderidos a células do centro folicular. Os centrócitos que expressam imunoglobulina de superfícies têm um local de combinação com o anticorpo alterado comparado com suas células progenitoras, devido a mutações somáticas, as quais podem ter sofrido troca de classe da cadeia pesada. Os centrócitos com mutações que resultam em afinidade reduzida pelo antígeno rapidamente morrem por apoptose, enquanto os centrócitos com mutações que resultam em afinidade aumentada são capazes de se ligar ao antígeno apresentado pelas células dendríticas foliculares. Este processo as "salva" da apoptose e elas re-expressam a proteína BCL2. Por meio da interação com moléculas de superfície nas células dendríticas e células
T, como os ligantes CD23 e CD40, os centrócitos inibem a expressão da proteína BCL6, e se diferenciam ou em células de memória ou em células do plasma.

Acredita-se que os linfomas foliculares sejam células B do centro germinativo tumorais (centrócitos e centroblastos), nos quais os centrócitos falham ao sofrer apoptose devido ao seu rearranjo cromossomal, t $(14 ; 18)$, que promova a expressão da proteína BCL2 normal. As células $\mathrm{B}$ de memória tipicamente residem na zona marginal folicular (zona marginal de células B). As células B de memória e as células do plasma têm a região IGV do gene mutada, mas não continuam a sofrer mutações, não mostrando desta forma diversidade intraclonal. As células B do centro pós-germinativo possuem a habilidade de voltarem nos tecidos que sofreram estimulação antigênica, provavelmente por meio da expressão de integrinas de superfície, por isso as células que surgem no tecido linfóide associado a mucosa (MALT) tendem a retornar lá, enquanto aquelas que surgem nos nódulos linfáticos retornarão aos locais de medula nodal. Os linfomas da zona marginal do MALT, esplênico e tipos nodais correspondem ao centro pós-germinativo, possivelmente as células B de memória do tipo zona marginal, derivam e proliferam especificamente nos tecidos extranodais, esplênicos e nodais $^{2}$. A Figura 1 apresenta um esquema da diferenciação dos linfócitos B, mostrando a provável alteração patológica pontual em que se desenvolve o LDGCB.

\section{Imunofenótipo}

O LDGCB expressa vários marcadores B como o CD19, CD20, CD22 e o CD79a, mas um ou mais destes marcadores podem estar ausentes. A imunoglobulina citoplasmática e/ou de superfícies (IgM, $\operatorname{IgG}, \operatorname{IgA}$ ) pode ser demonstrada em 50-75\%. A imunoglobulina citoplasmática é freqüentemente vista em casos exibindo diferenciação plasmocítica. Enquanto a vasta maioria de linfomas de células grandes B anaplástico expressam CD30, casos não anaplásticos podem eventualmente marcar para CD30. Alguns casos expressam CD5 (10\%)

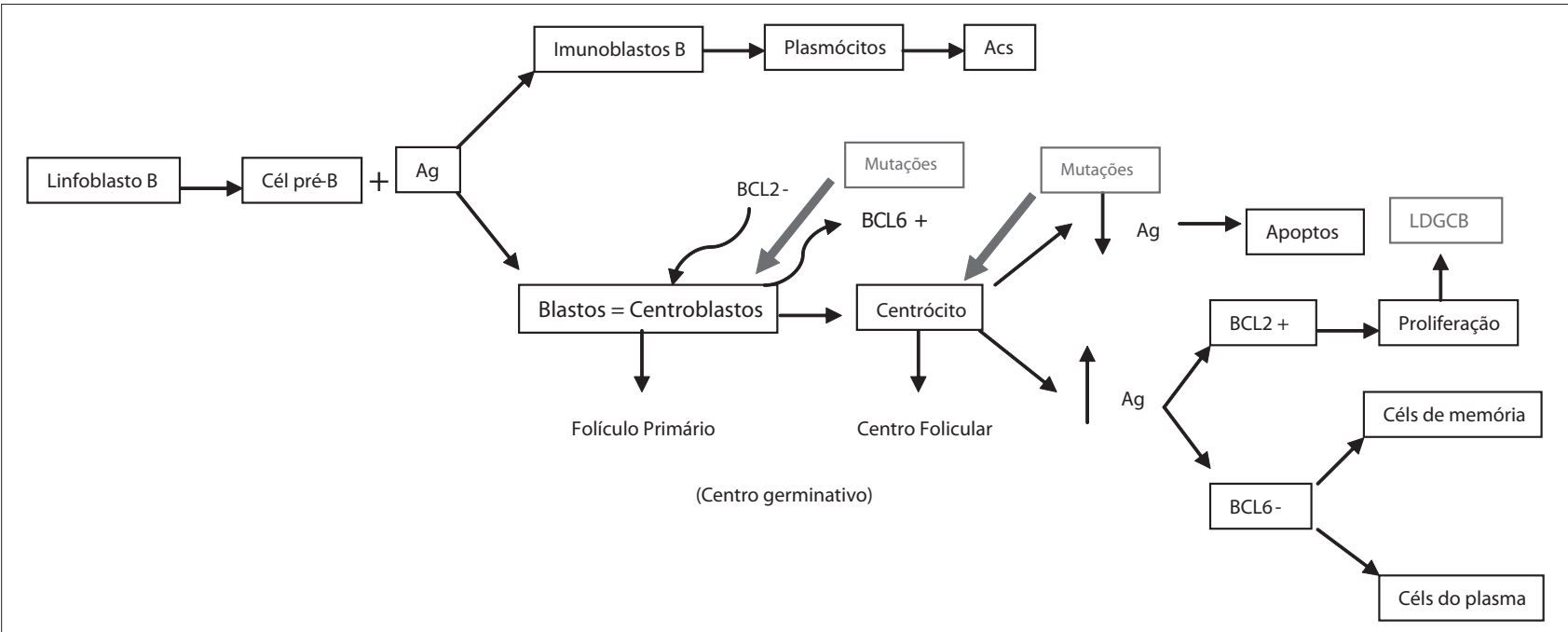

Figura 1 - Esquema da diferenciação dos linfócitos B 
ou CD10 (25-50\%). CD5+ LDGCB são negativos para expressão de ciclina D1 distinguindo as de variantes blastóides do linfoma celular do manto. CD5+ LDGCB devem se originar de novo melhor do que como manifestação da progressão de LLP/LLC. O BCL2 é positivo em aproximadamente $30-50 \%$ dos casos. A expressão nuclear do BCL6 é encontrada em uma alta proporção dos casos. A expressão da proteína P53, geralmente associada com mutações de TP53 pode ser observado em uma minoria dos casos. A expressão de marcadores associados a células do plasma como a sindecan (CD138) é vista em uma minoria dos casos. A fração proliferativa como detectado pela marcação Ki-67 geralmente é alta (maior que 40\%) e pode ser maior do que $90 \%$ em alguns casos ${ }^{1}$.

\section{Genética}

A maioria dos casos tem um rearranjo dos genes da cadeia pesada e da cadeia leve da imunoglobulina e apresentam mutações somáticas na região variável. A translocação do gene BCL2, por exemplo a translocação t (14;18), é uma marca do linfoma folicular, ocorre em 20 a 30\% dos casos. Aproximadamente $30 \%$ dos casos apresentam anormalidades da região 3q27 envolvendo o proto-oncogene cadidato BCL6. O rearranjo MYC é raro. Muitos casos exibem complexas anormalidades citogenéticas. A infecção das células neoplásicas pelo EBV pode ser observada e é mais comum em casos associados com imunodeficiência. Um estudo recente empregando DNA microarrays identificou duas categorias moleculares com padrão de expressão de genes sugestivo de diferentes estágios de desenvolvimento da célula B. Um tipo tinha um perfil de expressão característico de células B do centro germinativo, enquanto o outro tipo tinha um perfil similar ao de células B do sangue periférico ativadas in vitro ${ }^{1}$.

\section{Tecidos envolvidos}

Os pacientes podem apresentar com uma doença nodal ou extranodal. Cerca de 40\% são inicialmente confinados ao local extranodal. O local extranodal mais comum é o trato gastrointestinal (estômago ou região íleo-ceco), mas qualquer local extranodal pode ser um local primário de desenvolvimento incluindo a pele, sistema nervoso central, ossos, testículos, tecidos moles, glândulas salivares, trato genital feminino, pulmão, rim, fígado e baço. A apresentação primária com envolvimento de medula óssea e/ou sangue periférico é raro. Variantes morfológicas são mais prevalentes em regiões particularmente extranodais. Por exemplo, o LDGCB primário em tecido ósseo freqüentemente exibe núcleos multilobulados. Os pacientes geralmente apresentam um aumento rápido da massa sintomática em um único local nodal ou extranodal, com doença disseminada ${ }^{1}$.

\section{Prognóstico e tratamento}

O LDGCB é um linfoma agressivo, heterogêneo, mas potencialmente curável com quimioterapia multiagente; aproximadamente $40 \%$ dos casos que aparecem são curados com tratamento agressivo conten- do adriamicina. O International Prognostic Index (IPI) baseado em parâmetros clínicos é fortemente preditivo das conseqüências clínicas, mas sozinho não é capaz de prever com certeza o resultado de um tratamento para pacientes individuais, refletindo somente a biologia do tumor de maneira indireta. Uma alta taxa proliferativa tem sido associada com uma taxa de sobrevivência pior em alguns casos, enquanto a expressão de BCL2 tem sido associada com uma doença adversa de sobrevivência livre. A super expressão do gene P53 na maioria das células malignas é um outro indicador prognóstico adverso. Embora vários estudos tenham relatado um prognóstico ligeiramente ruim imunoblástico sobre a variante centroblástica, outros estudos falharam ao confirmar tal fato. Em alguns estudos, a translocação BCL6 tem sido relatada estar associada a um melhor prognóstico. Pacientes com LDGCB centro germinativo tipo B tinham uma melhor taxa de sobrevivência do que aqueles cujos linfomas eram tipo B ativados ${ }^{1}$.

Aproximadamente $60 \%$ dos pacientes com LDGCB recaem depois de um tratamento convencional baseado em antraciclina combinada com ciclofosfamida, adriamicina, vincristina, bleomicina e prednisolona ${ }^{4}$.

Várias tentativas têm sido feitas com o objetivo de aumentar a taxa de sobrevivência destes pacientes, porém sem sucesso². Para melhorar o resultado destes pacientes, os médicos precisam primeiro ser capazes de identificar no momento do diagnóstico os pacientes de alto risco, e segundo, desenvolver estratégias alternativas de tratamento, como terapia com anticorpos ou novas combinações de quimioterapia que podem ser efetivamente testadas.

Cada um dos subtipos de LDGCB citados anteriormente apresenta diferentes prognósticos, e a identificação e conhecimento adequado deles pode levar a avanços no tratamento terapêutico³.

Portanto, ainda há a necessidade de se utilizar métodos adicionais ou marcadores para identificar pacientes de alto risco no diagnóstico, e para melhorar a definição da expressão de genes específicos para se delinear intervenções terapêuticas ${ }^{4}$.

\section{Principais exames laboratoriais utilizados no diagnóstico de LDGCB}

\section{Anatomia patológica}

O exame de anatomia patológica é realizado com o tecido enviado para biópsia, que é embebido em parafina, cortado em finas partículas no micrótomo, fixado sobre uma lâmina e corado para observação no microscópio óptico. Este é um dos principais exames citológicos realizados no diagnóstico de LDGCB, pois por meio da morfologia celular e do predomínio do tipo celular observado pode-se ter uma idéia do tipo de LDGCB que o paciente possui, funcionando como um indicativo de que tipos de exames complementares são necessários para confirmar o diagnóstico.

A avaliação morfológica está baseada pela classificação WHO da Organização Mundial de Saúde para o diagnóstico de $L D G C B^{5,6} \mathrm{e}$ 
é completada com a subclassificação a qual é realizada de acordo com os critérios da classificação de Kiel, seguida de algumas modificações como:

- centroblástico, quando $90 \%$ ou mais das células tumorais eram tipicamente centroblastos;

- centroblástico polimórfico, no qual a proporção de imunoblastos varia de 10 a $90 \%$ das células tumorais,

- imunoblástico, quando $90 \%$ ou mais das células tumorais são de imunoblastos.

Adicionalmente, LDGCB são plasmablásticos quando as células tumorais expressam um fenótipo de diferenciação de célula do plasma (CD20-, CD79a+) com morfologia de linfoma de célula grande imunoblástico. Para comparação entre diferentes grupos na análise estatística, linfomas centroblásticos polimórficos são adicionalmente subclassificados em casos com $50 \%$ ou menos, ou mais do que $50 \%$ de imunoblastos. Casos com $50 \%$ ou mais de imunoblastos são classificados no subgrupo imunoblástico, e casos que não preenchem os critérios morfológicos são considerados como não classificáveis pelos pesquisadores.

\section{Análise citogenética}

A análise citogenética pode ser realizada por meio da citogenética clássica e da citogenética molecular que utiliza mais comumente a técnica de FISH (Hibridização in situ por Fluorescência), ambas baseadas na análise de cariótipo do indivíduo. Porém, com algumas diferenças, enquanto a citogenética clássica baseia sua análise na observação dos cromossomos metafásicos do indivíduo por meio da cultura de células, que leva em média 72 horas para atingir o ponto ideal para interrupção do crescimento celular e análise do material, a técnica de FISH permite que o exame seja realizado ainda em núcleos interfásicos, necessitando de um tempo de cultura muito menor, por meio da utilização de sondas marcadas com fluorocromos, que se hibridizarão em segmentos específicos da cromatina. Conforme relatado anteriormente, são vários os tecidos envolvidos no LDGCB, portanto a escolha do material adequado para a realização das culturas de células é imprescindível para conseguir mostrar a alteração cromossômica. Devido a isso, deve-se avaliar com muita cautela um resultado de cariótipo baseado no tipo de material estudado para se prevenir casos falso-negativos.

Os resultados mais observados em pacientes com LDGCB são as translocações entre os cromossomos 11 e 18, e entre os cromossomos 14 e 18. Tanto a t $(11 ; 18)$ (q32;q21) quanto a t $(14 ; 18)$ (q32;q21) são características do linfoma folicular sendo consideradas os eventos iniciais da linfomagênese. Essas translocações representam o resultado de um erro durante o processo de recombinação VDJ, levando a desregulação da expressão do gene BCL2 anti-apoptótico, colocando-o próximo de um gene enhancer na cadeia pesada da imunoglobulina. A t $(14 ; 18)$ com o rearranjo do gene BCL2 já foi detectada em um terço dos casos de LDGCB. Porém, não se sabe ao certo se os casos com esta translocação representam um único tipo de LDGCB ou que papel esta tem na sua patogênese ${ }^{7}$. Alguns estudos não têm mostrado nenhum efeito ${ }^{8,9}$, enquanto outros têm mostrado um aumento na incidência de recaídas ${ }^{10}$, diminuição na respos- ta a terapia ou menor taxa de sobrevivência ${ }^{11}$, ou uma grande correlação com a doença ${ }^{12}$. Em alguns estudos há poucos resultados informativos, ou resistência ao tratamento; tem sido atribuída à expressão da proteína BCL2, melhor do que a translocação ${ }^{12-14}$. Essa inconsistência nos resultados, deve ser explicada em parte pela variação na metodologia utilizada para detectar a translocação em estudos anteriores ${ }^{10}$.

\section{Biologia molecular}

Por meio do DNA e/ou RNA extraído de linfoma de células B podem ser realizadas as técnicas de reação em cadeia da polimerase (PCR), RT-PCR, southern blotting, microssatélite (utilizando marcadores específicos) e microarray para o diagnóstico do LDGCB.

A técnica de PCR utilizando oligonucleotídeos específicos para amplificar os genes BCL-2 e JH (gene da cadeia de imunoglobulina).

A técnica de microarray ou DNA-chip, mede o nível de expressão de milhares de genes ao mesmo tempo. Esta técnica é utilizada na detecção e quantificação de ácidos nucléicos (RNAm na foram de cDNA ou DNA genômico) provenientes de amostras biológicas, as quais são colocadas para hibridar com o DNA fixado em lâminas (hibridação por complementariedade de bases). O resultado deste exame é obtido por meio da geração de uma imagem de hibridação, que é obtida por meio de leitores (scanners) a laser. O microarray é utilizado para determinação do perfil de expressão gênica de cada indivíduo. Para preparação dos microarrays utilizam-se robôs altamente precisos que aplicam as diferentes amostras de DNA em diminutos pontos no centro de uma lâmina de microscópio com a superfície quimicamente preparada.

Atualmente os microarrays também podem ser realizados em tecidos embebidos em parafina, sendo a técnica denominada de Microarray em Tecido (TMA). A Tabela 1 apresenta os marcadores que foram utilizados por alguns autores para análise do perfil de expressão gênica. Os anticorpos selecionados reconhecem moléculas cuja expressão de RNAm é altamente associada com o grupo GCB ou não GCB em estudos com cDNA microarray.

\section{Imunohistoquímica}

A expressão de antígenos individuais relacionados a diferentes estágios de diferenciação da célula B deve ajudar a definir grupos de tumores com diferentes características clínicas e patológicas. De fato, alguns estudos observaram um potencial prognóstico da expressão individual destes antígenos ${ }^{5}$. A Tabela 2 apresenta o painel de anticorpos monoclonais utilizados pelos autores. Depois da incubação do tecido com os anticorpos primários a reação ocorre. O resultado é considerado positivo de acordo com a porcentagem de células marcadas com o anticorpo. Existem vários estudos utilizando painel imunohistoquímico subdividindo os LDGCBs em subgrupos prognosticamente importantes. Porém, os dados resultantes têm sido controversos, com muitos estudos mostrando uma melhor taxa de sobrevivência para o grupo GCB e outros que não apresentam nenhuma diferença na taxa de sobrevivência entre os grupos GCB e não $\mathrm{GCB}^{5,6,15,16}$ 
Tabela 1 - Marcadores utilizados na análise de TMA (Microarray em tecido)

\begin{tabular}{|c|c|c|c|c|c|}
\hline \multirow{2}{*}{ Marcadores } & \multicolumn{5}{|c|}{ Autores } \\
\hline & Tzankov et al., 2003'16 & lqbal et al., $2004^{21}$ & Hans et al., 2004 ${ }^{17}$ & Oh, Park $2006^{22}$ & Tzankov et al., $2006^{6}$ \\
\hline $\mathrm{Bcl}-2$ & $x$ & $x$ & $x$ & $x$ & $x$ \\
\hline $\mathrm{Bcl}-6$ & $x$ & $x$ & $x$ & $x$ & $x$ \\
\hline CD10 & $x$ & $x$ & $x$ & $x$ & $x$ \\
\hline MUM1 & & & $x$ & $x$ & \\
\hline CD20 & $x$ & & $x$ & & $x$ \\
\hline CD138 & & & & $x$ & \\
\hline MIB1 & & & & $\mathrm{x}$ & \\
\hline FOXP1 & & & $x$ & & \\
\hline Ciclina-D2 & & & $x$ & & \\
\hline
\end{tabular}

Tabela 2 - Painel de anticorpos monoclonais usados em imuhistoquímica

\begin{tabular}{|c|c|c|c|c|c|}
\hline \multirow{2}{*}{ Marcadores } & \multicolumn{5}{|c|}{ Autores } \\
\hline & Barrans et al., 2003 & Huang et al., 20027 & Tzankov et al., $2003^{16}$ & Colomo et al., $2003^{5}$ & Tzankov et al., 2006 \\
\hline BCL-6 & $x$ & $x$ & $x$ & $x$ & $x$ \\
\hline CD10 & & $\mathrm{x}$ & $x$ & $x$ & $x$ \\
\hline CD20 & & & $x$ & $x$ & $x$ \\
\hline $\mathrm{Bcl}-2$ & $x$ & $x$ & $x$ & $x$ & $x$ \\
\hline CD44v4 & & & $x$ & & \\
\hline CD44v6 & & & $x$ & & \\
\hline CD44v9 & & & $x$ & & \\
\hline CCNE & & & & $x$ & \\
\hline CCND1 & & & & $x$ & \\
\hline CCND3 & & & & $x$ & \\
\hline P27 & & & & $x$ & $x$ \\
\hline Ki-67 & & & & $x$ & \\
\hline CCNB1 & & & & $x$ & \\
\hline MUM1 & & & & $x$ & $x$ \\
\hline CD79 & & & & & $x$ \\
\hline CD3 & & & & & $x$ \\
\hline CD5 & & & & & $x$ \\
\hline CD138 & & & & & $x$ \\
\hline P53 & & & & & $x$ \\
\hline CD44s & & & $x$ & $X$ & \\
\hline
\end{tabular}

\section{Imunofenotipagem}

A citometria de fluxo é um método moderno do estudo de células. Por meio desta, múltiplas propriedades físicas e biológicas de uma célula podem ser determinadas. A população de células e subpopulações em uma amostra podem ser determinadas pelo número e tipo de antígeno de superfície, citoplasmático ou mesmo nuclear, o que propicia sua quantificação e classificação imunológica (imunofenótipo). Em adição, a citometria permite um rastreamento rápido de um grande número de células, e por esta técnica um número pequeno de células neoplásicas pode ser detectada entre um grande número de células normais.
A Tabela 3 apresenta os principais antígenos utilizados para definir as linhagens precursoras de células B.

\section{Discussão}

Dada a importância do diagnóstico precoce e urgência no início do tratamento correto, que juntos auxiliam na melhora do paciente e aumentam sua expectativa de vida, existe uma ansiedade para se determinar qual o melhor método para o diagnóstico do LDGCB e os principais marcadores preditivos da taxa de sobrevivência. 
Tabela 3 - Principais antígenos utilizados na definição de linhagens precursoras de células B

\begin{tabular}{|c|c|c|c|}
\hline \multicolumn{2}{|c|}{ Principais antígenos utilizados em Hematologia } & \multirow[b]{2}{*}{ Células que expressam } & \multirow[b]{2}{*}{ Função } \\
\hline CD & Anticorpos monoclonais & & \\
\hline CD 1a & Leu6 T6 BL6 NA1/34 & $\begin{array}{l}\text { Céls. T tímicas, subgrupo de céls. B, céls. De } \\
\text { Langerhans }\end{array}$ & Glicoproteína 48 kD que se liga a b2-microglobulina \\
\hline CD5 & LEU1 T1 BL1a DK23 & Céls. T maduras e tímicas, subgrupo de céls. B & Ativação de céls. T, ligante de CD72 \\
\hline CD10 & CALLA J5 ALB1 SS2/36 & $\begin{array}{l}\text { Precursor B e céls. Do centro germinativo; algumas } \\
\text { céls. Tímicas PMN }\end{array}$ & Endopeptidase neutra \\
\hline CD14 & $\begin{array}{l}\text { LEU M3 My4 RM052 } \\
\text { TUK4 }\end{array}$ & Monócitos maduros; leve reação em algumas céls. B & Aminopeptidase N \\
\hline CD19 & LEU12 B4 J4.119 HD37 & Céls. B precursoras e maduras & Ativação de céls. B \\
\hline CD20 & LEU 16 B1 Bly-1 Bly-1 & Céls. B precursoras tardios e maduras & Canal de $\mathrm{Ca}^{2+}$. Ativação de céls. $\mathrm{B}$ \\
\hline CD22 & $\begin{array}{l}\text { LEU14 B3 SJ10.1H11 } \\
\text { T015 }\end{array}$ & Céls. B precursoras e maduras & Molécula de adesão celular \\
\hline CD43 & $\begin{array}{l}\text { Leu 22, leucosialina, } \\
\text { sialoforina }\end{array}$ & Céls. T, céls. Mielóides, alguns linfomas B & Liga-se ao CD45(ICAM-1) e pode ser anti-adesivo \\
\hline CD45R0 & UCHL1 & $\begin{array}{l}\text { Subgrupo de céls B, subgrupo de T (memória), } \\
\text { monócitos, macrófagos }\end{array}$ & Transdução de sinal: tirosina-fosfatase \\
\hline CD45RA & $2 \mathrm{H} 4$ & Céls $B$, subgrupo de céls $T$ (virgem), monócitos & Transdução de sinal: tirosina-fosfatase \\
\hline CD45RB & T200 & $\begin{array}{l}\text { Subgrupos de céls T, céls B, monócitos, macrófagos, } \\
\text { granulócitos }\end{array}$ & Transdução de sinal: tirosina-fosfatase \\
\hline CD79a & HM57 & Céls B precursoras e maduras & $\begin{array}{l}\text { Mb-1: transdução de sinal da lg de superfície para o } \\
\text { citoplasma }\end{array}$ \\
\hline HLA-DR & la 7.2 & $\begin{array}{l}\text { Céls B monócitos, progenitors mielóides e céls T } \\
\text { ativadas }\end{array}$ & Antígenos de apresentação MHC classe II \\
\hline $\lg M \mathrm{~m}$ & & Céls $B$ virgens & Reconheciemento de $\mathrm{Ag}$, ativação de céls $\mathrm{B}$ \\
\hline $\lg \mathrm{g}$ & & Céls B de memória & $\begin{array}{l}\text { Reconhecimento de Ag, ativação de céls B, imuni- } \\
\text { dade humoral }\end{array}$ \\
\hline $\lg D d$ & & Céls $B$ virgens & Reconhecimento de $\mathrm{Ag}$, ativação de céls $\mathrm{B}$ \\
\hline $\lg \mathrm{A} a$ & & Céls B de memória & $\begin{array}{l}\text { Reconhecimento do Ag, ativação de céls } B \text {, imuni- } \\
\text { dade de mucosas }\end{array}$ \\
\hline $\lg \mathrm{E} e$ & & Céls B de memória & $\begin{array}{l}\text { Reconhecimento de } A g \text {, ativação de céls } B \text {, reação de } \\
\text { hipersensibilidade }\end{array}$ \\
\hline k & & Céls B & Ativação de céls $B$ \\
\hline I & & Céls B & Reconhecimento do $\mathrm{Ag}$, ativação das céls $\mathrm{B}$ \\
\hline
\end{tabular}

O exame de anatomia patológica pode ser utilizado como um exame de referência servindo de base para se delinear qual o diagnóstico do paciente e auxiliar na definição de quais exames complementares são necessários para se definir o diagnóstico, visto que só observando a morfologia celular não é possível chegar a um diagnóstico preciso.

A marcação por imunohistoquímica já é um método amplamente utilizado. A imunomarcação permite ainda, realizar uma avaliação direta das células neoplásicas. Por outro lado, o método de expressão gênica realizado por meio da técnica de microarray, que permite a análise do perfil de expressão de milhares de genes ao mesmo tempo, requer amostras de tumores frescos ou congelados, os quais nem sempre estão disponíveis em muitos casos, e às vezes falham na produção de resultados $(6,6 \%$ dos casos observados por este grupo) $)^{17}$.
Além disso, após a microdissecção, o tecido submetido à análise de cDNA contém não somente tumor mas também tecido não tumoral. Caso haja uma quantidade significante de tecido não tumoral presente, os dados de expressão de cDNA podem não refletir o perfil de expressão gênica do tumor. A classificação por meio do cDNA pode não ter uma boa sensibilidade devido à presença de tecido de nódulo linfático ou do centro germinativo normais nas amostras de DNA, que podem culminar com um resultado duvidoso. A presença de tecido estromal na amostra de cDNA deve influenciar também o resultado da expressão gênica. A classificação TMA apresenta uma sensitividade de $70 \%$ para o grupo GCB e $87 \%$ para o grupo não GCB, e o valor preditivo positivo desta classificação é de $84 \%$ para o GCB e de $74 \%$ o grupo não $\mathrm{GCB}^{17}$.

Embora o TMA seja uma ferramenta de pesquisa, os resultados da imunomarcação com TMA concordam com a marcação das secções de 
tecidos em $86 \%$ a $100 \%$ dos casos e com o aumento no número de amostras, também aumenta o nível de concordância. Usando quatro centros de amostras por caso, a concordância entre o TMA e as secções marcadas é de $97 \%$ a $100 \%{ }^{5}$. Além disso, quando se compara com secções inteiras marcadas por imunohistoquímica, há uma melhor consistência na imunomarcação entre os casos porque a maioria deles está no mesmo local das secções de TMA. A quantificação dos resultados da marcação neste caso é mais fácil porque o centro do tecido pode ser completamente visto sob um campo intermediário no microscópio, e cada caso pode ser avaliado em questão de segundos. Outra vantagem é que o uso do método de TMA preserva os tecidos nos blocos de parafina para estudos futuros. Apesar da TMA ser uma técnica altamente sensível no diagnóstico do LDGCB seu elevado custo impede que ela seja usada na rotina laboratorial. Porém, para análise do material mais de um observador é necessário, devido à intensidade da marcação que varia entre os casos e por causa da diferença de preservação dos tecidos. Somente uma proporção relativa de células tumorais marcadas positivamente e algumas com intensidades de marcação são consideradas, tornando este tipo de análise um pouco subjetiva.

Rosenwald et al. tentaram utilizar o perfil de expressão de genes para formular um preditor molecular de sobrevivência independente do score IPI, baseando-se em uma combinação de quatro diferentes perfis de expressão de genes (célula B do centro germinativo, MIIC classe II, nódulo linfático e proliferação), juntamente com a expressão RNAm BMP-6, porque não há expressão de um gene único que possa predizer com certeza as conseqüências para todos os pacientes ${ }^{18-20}$. No entanto, poucos centros que realizam o diagnóstico de rotina dos linfomas têm acesso à tecnologia de perfil de expressão gênico por microarray.

A maior parte dos diagnósticos de linfoma é feito em tecidos embebidos em parafina, e amostras frescas ou congeladas, que não são freqüentemente utilizadas para extração de RNA. É importante, portanto, que reagentes como anticorpos para análise imunohistoquímica sejam desenvolvidos e capazes de fazer a avaliação de rotina para identificar marcadores do subtipo da doença pelo perfil de expressão de gene estudado. A marcação imunohistoquímica de uma série de casos de LDGCB em tecido de microarray (TMA) usando somente três anticorpos monoclonais CD10, MUMI e BCL6 tem se mostrado suficiente para identificar os subtipos centro germinativo (GC) e não GC dos LDGCBs e predizer a sobrevivência com uma expressão similar a de expressão de genes por microarrays ${ }^{17}$.

O exame de imunofenotipagem permite a caracterização do estádio de maturação das células malignas contribuindo para a de- finição do diagnóstico, a definição da linhagem celular é uma técnica rápida, precisa, quantitativa e reprodutível. Porém, necessita de pessoal extremamente treinado, e sozinho também não se consegue definir um diagnóstico.

A técnica de PCR é rápida, apresenta uma alta sensibilidade e especificidade, porém depende da qualidade do DNA extraído, visto que as amostras de DNA extraídas dos tecidos parafinizados apresentam uma baixa qualidade, o que dificulta a realização desta técnica, tornando a interpretação dos seus resultados em larga escala difícil, assim como as técnicas de southern blotting e de microssatélite.

A citogenética clássica permite observar outros marcadores além dos específicos para o LDGCB, que são as t $(14 ; 18)$ e t $(11 ; 18)$, além de se poder encontrar alterações secundárias. No entanto, dependendo do tipo de tecido analisado e do tamanho da alteração cromossômica não é possível detectar por esta técnica. Além disso, pode haver ausência de metáfases na cultura celular realizada, a morfologia e padrão de estiramento dos cromossomos podem estar ruins, o que prejudica um diagnóstico preciso.

Por outro lado à técnica de FISH permite que a análise do material seja realizada ainda em núcleos em intérfase (reduzindo o tempo do resultado) e em tecidos embebidos em parafina. Porém, a definição de uma translocação necessita da qualidade da reação, uma boa refringência e nenhuma sobreposição, além de uma boa hibridização para minimizar os riscos de falso positivos. A t $(14 ; 18)$ foi detectada em 23 de 28 (82\%) casos usando PCR em material congelado e em 8 de 20 (29\%) dos mesmos casos que tinham sido feitos com DNA amplificado de tecidos embebidos em parafina. Usando FISH, 24 de 26 amostras congeladas e 26 de 28 amostras embebidas em parafina tinham a translocação detectada. Todos os casos que eram positivos pela PCR também eram positivos pela técnica de FISH. Ambos PCR e FISH são altamente eficientes na detecção da t $(14 ; 18)$ em tecidos não fixados. Porém, quando somente blocos de parafina estão disponíveis para análise, a técnica de FISH apresenta-se como o melhor método de escolha sendo capaz de atingir uma sensibilidade de $100 \%$. Como um controle adicional a técnica de FISH foi comparada com o bandamento $G$ e houve uma concordância dos resultados ${ }^{10}$.

Portanto, de todas as técnicas testadas até o momento a de FISH é a mais adequada para o diagnóstico de LDGCB, sendo superior à técnica de PCR, podendo ser ainda aplicada em materiais embebidos em parafina, porém em nosso país ainda encontramos obstáculos econômicos para a ampla utilização desta metodologia no diagnóstico e acompanhamento desses pacientes. 


\section{Referências}

1. Gatter KC, Warnke RA. Diffuse large B-cell lumphoma. Pathology and genetics of tumours of the haematopoietic and lymphoid system. Lyon: IARC Press; 2001. p. 171-4.

2. Fisher RI, Gaynor ER, Dahlberg S, Oken MM, Grogan TM, Mize EM et al. Comparison of a standard regimen (CHOP) with three intensive chemotherapy regimens for advanced non-Hodgkin's lymphoma. N Engl J Med 1993;328(14):1002-6.

3. Harris NL. Mature B-cell neoplasms: introduction. Lyon: IARC Press; 2001. p. 121-6.

4. Banham AH, Connors JM, Brown PJ, Cordell JL, Ott G, Screenivasan G et al. Expression of the FOXP1 transcription factor is strongly associated with inferior survival in patients with diffuse large B-cell lymphoma. Clin Cancer Res 2005;11(3):1065-72.

5. Colomo L, López-Guillermo A, Perales M, Rives S, Martínez A, Bosch F et al. Clinical impact of the differentiation profile assessed by immunophenotyping in patients with diffuse large B-cell lymphoma. Blood 2003;101(1):78-84.

6. Tzankov A, Gschwendtner A, Augustin F, Fiegl M, Obermann EC, Dirnhofer $S$ et al. Diffuse large B-cell lymphoma with overexpression of cyclin $e$ substantiates poor standard treatment response and inferior outcome. Clin Cancer Res 2006:12(7Pt1):2125-32

7. Huang JZ, Sanger WG, Greiner TC, Staudt LM, Weisenburger DD, Pickering $\mathrm{DL}$ et al. The $\mathrm{t}(14 ; 18)$ defines a unique subset of diffuse large B-cell lymphoma with a germinal center B-cell gene expression profile. Blood 2002;99(7):2285-90

8. Gascoyne RD, Adomat SA, Krajewski S, Krajewska M, Horsman DE, Tolcher AW et al. Prognostic significance of Bcl-2 protein expression and Bcl-2 gene rearrangement in diffuse aggressive non-Hodgkin's lymphoma. Blood 1997;90(1):244-51.

9. Vitolo U, Gaidano G, Botto B, Volpe G, Audisio E, Bertini M et al. Rearrangements of bcl-6, bcl-2, c-myc and $6 q$ deletion in B-diffuse large-cell lymphoma: clinical relevance in 71 patients. Ann Oncol 1998;9(1):55-61

10. Barrans SL, Evans PA, O'Connor JM, Kendall SJ, Owen RG, Haynes AP et al. The $t(14 ; 18)$ is associated with germinal center-derived diffuse large B-cell lymphoma and is a strong predictor of outcome. Clin Cancer Res 2003;9(6):2133-9

11. Tang SC, Visser L, Hepperle B, Hanson J, Poppema S. Clinical significance of bcl-2 MBR gene rearrangement and protein expression in diffuse large-cell non-Hodgkin's lymphoma: an analysis of 83 cases. J Clin Oncol 1994;12(1):149-54.
12. Kramer MH, Hermans J, Wijburg E, Philippo K, Geelen E, van Krieken JH. Clinical relevance of BCL2, BCL6, and MYC rearrangements in diffuse large B-cell lymphoma. Blood 1998;92(9):3152-62.

13. Hill ME, MacLennan KA, Cunningham DC, Vaughan Hudson B, Burke $\mathrm{M}$, Clarke $\mathrm{P}$ et al. Prognostic significance of BLC-2 expression and bcl-2 major breakpoint region rearrangement in diffuse large cell non-Hodgkin's Iymphoma: a British National Lymphoma Investigation Study. Blood 1996;88(3):1046-51

14. Kramer MH, Hermans J, Parker J, Krol AD, Kluin-Nelemans JC, Haak HL et al. Clinical significance of bcl-2 and p53 protein expression in diffuse large B-cell lymphoma: a population based study. J Clin Oncol 1996;14(7):2131-8.

15. Barrans SL, Carter I, Owen RG, Davies FE, Patmore RD, Haynes AP et al. Germinal center phenotype and bcl-2 expression combined with the International Prognostic Index improves patient risk stratification in diffuse large B-cell lymphoma. Blood 2002;99(4):1136-43

16. Tzankov A, Pehrs AC, Zimpfer A, Ascani S, Lugli A, Pileri S et al. Prognostic significance of CD44 expression in diffuse large $B$ cell lymphoma of activated and germinal centre B cell-like types: a tissue microarray analysis of 90 cases. J Clin Pathol 2003;56(10):747-52.

17. Hans $\mathrm{CP}$, Weisenburger DD, Greiner TC, Gascoyne RD, Delabie J, Ott G et al. Confirmation of the molecular classification of diffuse large B-cell lymphoma by immunohistochemistry using a tissue microarray. Blood 2004;103(1):275-82

18. Alizadeh AA, Eisen MB, Davis RE, Ma C, Lossos IS, Rosenwald A et al. Distinct types of diffuse large $B$-cell lymphoma identified by gene expression profiling. Nature 2000;403(6769):503-11.

19. Rosenwald A, Wright G, Chan WC, Connors JM, Campo E, Fisher Rl et al. The use of molecular profiling to predicte survival after chemotherapy for diffuse large-B-cell lymphoma. N Engl J Med 2002;346(25):1937-47.

20. Wright G, Tan B, Rosenwald A, Hurt EH, Wiestner A, Staudt LM. A gene expression-based method to diagnose clinically distinct subgroups of diffuse large B cell lymphoma. Proc Natl Acad Sci USA 2003;100(17):9991-6.

21. Iqbal J, Sanger WG, Horsman DE, Rosenwald A, Pickering DL, Dave B et al. BCL2 translocation defines a unique tumor subset within the germinal center B-cell-like diffuse large B-cell lymphoma. Am J Pathol 2004:165(1):159-66.

22. Oh YH, Park CK. Prognostic evaluation of nodal diffuse large B cell lymphoma by immunohistochemical profiles with emphasis on CD138 expression as a poor prognostic factor. J Korean Med Sci 2006;21(3):397-405. 